(median [interquartile range] from $10.2[6.5-17.1]$ to 6.0 [3.9-15.6] $\mathrm{mg} / \mathrm{L} ; \mathrm{p}=0.02$ ), but not in the control group (from $8.7[5.2-17.2]$ to $13.2[7.9-20.1] \mathrm{mg} / \mathrm{L} ; \mathrm{p}=0.70$ ). A similar trend was seen for serum calprotectin $(p=0.065$ in intervention versus $\mathrm{p}=0.31$ in control), but not for ESR. In addition, ASDAS-CRP $(\mathrm{p}=0.02)$, BASDAI $(p=0.04)$, SF-36 physical component score $(p=0.01), E Q-5 D(p=0.049)$, and EQ$5 D$ VAS $(p=0.02)$ decreased significantly in the intervention group, but not the control group.

Conclusions: This proof-of-concept study in axSpA revealed a significant decrease in serum CRP levels upon add-on training program, in the absence of safety signals. Together with the significant improvement in disease activity and quality of life, these findings warrant full-scale randomised controlled trials of this novel therapeutic approach in patients with axSpA and other inflammatory conditions.

Disclosure of Interest: None declared

DOI: 10.1136/annrheumdis-2018-eular.1820

\section{SAT0285 EFFICACY OF EARLY VERSUS DELAYED INITIATION OF ANTI-TNF-ALPHA TREATMENT IN AXIAL SPONDYLOARTHRITIS. DATA FROM THE CZECH REGISTRY ATTRA}

H. Mann ${ }^{1}$, K. Bubová ${ }^{1}$, J. Závada ${ }^{1}$, Š. Forejtová ${ }^{1}$, Z. Křístková ${ }^{2}$, L. Szczuková ${ }^{2}$, P. Horák ${ }^{3}$, J. Vencovský ${ }^{1}$, K. Pavelka ${ }^{1}$ on behalf of ATTRA registry. ${ }^{1}$ Institute of Rheumatology, Prague 2; ${ }^{2}$ Institute of Biostatistics and Analyses, Faculty of Medicine, Masaryk University, Brno; ${ }^{3}$ III Department of internal Medicine, Faculty of Medicine and Dentistry, Palacký University Olomouc, Olomouc, Czech Republic

Background: Anti-TNF- $\alpha$ agents are the mainstay of pharmacotherapy for patients with axial spondyloarthritis $(\mathrm{AxSpA})$ who failed treatment with NSAIDs. A little is known about the influence of early versus delayed treatment initiation on their clinical efficacy.

Objectives: To compare change of disease activity in AxSpA patients on anti$\mathrm{TNF}-\alpha$ therapy based on symptom duration prior to treatment initiation.

Methods: Baseline demographic data and efficacy parameters of patients starting their first anti-TNF- $\alpha$ treatment $\leq 10$ years (EARLY) or $>10$ years (DEALYED) after first symptoms of $\mathrm{AxSpA}$ from the Czech national registry ATTRA were compared. Mean $\pm S D$ and absolute/relative frequencies were used to describe continuous and categorical variables, respectively. P-value of Fisher's exact test and Mann-Whitney test is given when assessing difference between groups in categorical and continuous variables. ATTRA is a centralised prospective computerised registry of patients receiving bDMARD therapy for rheumatic diseases collecting data on efficacy, safety and quality of life of all patients treated in the Czech Republic. Anti-TNF- $\alpha$ therapy was indicated for patients with AxSpA who have failed treatment with NSAIDs with CRP $\geq 1 \mathrm{mg} / \mathrm{dl}$ and BASDAI score $\geq 4$.

Results: Data from 1290 axSpA patients were available for analysis. 618 patients started treatment $\leq 10$ years (EARLY) and $672>10$ years (DELAYED) after the onset of $\mathrm{AxSpA}$ symptoms. There was no significant difference in gender distribution (71.4 vs $72.5 \%$ males; $p=0.67$ ) or age at $A x S p A$ diagnosis $(33.3 \pm 10.4$ vs 33.5 $\pm 10.4 ; p=0.68)$ between the two groups. At the time of anti-TNF- $\alpha$ initiation EARLY patients were significantly younger $(36.4 \pm 10.6$ vs $44.0 \pm 11.2$ years; $\mathrm{p}<0.001)$ with shorter symptom duration $(5.5 \pm 2.7$ vs $18.9 \pm 8.1 ; p<0.001)$, but disease activity assessed by BASDAI $(6.3 \pm 1.8$ vs $6.3 \pm 1.6 ; p=0.81)$ and serum CRP levels $(2.6 \pm 2.5$ vs $2.4 \pm 2.0 \mathrm{mg} / \mathrm{dL} ; \mathrm{p}=0.34$ ) were comparable in both groups. Mean change of BASDAI scores from baseline during anti-TNF- $\alpha$ therapy was significantly greater in the EARLY group at all time-points $(3.7 \pm 2.5$ vs $3.4 \pm 2.2$ at month $3,4.2 \pm 2.5$ vs $3.8 \pm 2.3$ at month $6,4.4 \pm 2.5$ vs $4.0 \pm 2.3$ at month 12 and 4.4 \pm 2.5 vs $4.0 \pm 2.4$ at month $24 ; p<0,05$ for all) suggesting better treatment response. The difference in survival on therapy between the two groups was not statistically significant.

Conclusions: AxSpA patients starting anti-TNF- $\alpha$ therapy more than 10 years after onset of symptoms have significantly worse response to treatment compared to patients with earlier treatment initiation.

Acknowledgements: This study was supported by the project of MHCR for conceptual development of research organisation 00023728

Disclosure of Interest: None declared

DOI: 10.1136/annrheumdis-2018-eular.3610

\section{SAT0286 \\ RETENTION RATE AND SAFETY DATA OF BIOSIMILAR CT-P13 IN ANKYLOSING SPONDYLITIS PATIENTS: DATA FROM THE KOREAN COLLEGE OF RHEUMATOLOGY BIOLOGICS REGISTRY}

H.-A. Kim ${ }^{1}$, E.-Y. Lee ${ }^{2}$, S.-K. Lee ${ }^{3}$, Y.-B. Park ${ }^{4}$, K. Shin ${ }^{3} .{ }^{1}$ Department of Rheumatology, ${ }^{2}$ Department of Medical Informatics, Ajou University School of Medicine, Suwon; ${ }^{3}$ Department of Internal Medicine (Division of Rheumatology), Seoul Metropolitan Government-Seoul National University Hospital Boramae Medical Center, ${ }^{4}$ Department of Internal Medicine (Division of Rheumatology), Yonsei University College of Medicine, Severance Hospital, Seoul, Korea, Republic Of

Background: CT-P13 is a biosimilar prescribed in a number of countries for indications approved for the reference infliximab (RINF), including ankylosing spondylitis (AS), rheumatoid arthritis, and inflammatory bowel diseases. Clinical data of CT-P13 have been analysed in previous clinical trials, demonstrating equivalence of efficacy and pharmacokinetic profile to RINF. However, there are few studies showing long-term data of its drug survival or safety.

Objectives: To investigate the drug retention rate and safety data of biosimilar CT-P13 in Korean AS patients.

Methods: Subjects were AS patients enrolled in the Korean College of Rheumatology biologics registry (KOBIO). Data from patients who received RINF and CTP13 were included in the analysis ${ }^{\text {Dec } 2012} \sim$. Dec 2017 Discontinuation was defined as switching or stopping the biologic agent. Kaplan-Meier curve and Cox proportional hazard model were used for further analysis. Reason for RINF or CT-P13 discontinuation was also assessed.

Results: Data from 399 AS patients (CT-P13; 256, RINF; 143) were analysed. The mean age of patients was 39.0 in the CT-P13 group, and 73\% were males. The mean disease duration was 4.1 years. Eighty percent of patients were firsttime biologic users. Discontinuation of CT-P13 occurred in $30.9 \%$ (switching in $17.6 \%$ ) of patients during follow-up. The drug retention rate of first-line users of CT-P13 was marginally higher compared with second or more $(\geq 2)$-line users of CT-P13, first-line users of RINF, and $\geq 2$ line users of CT-P13 in Korean AS patients $(p=0.0518)$. The reason of discontinuation was inefficacy $(42.7 \%)$, adverse events $(20.2 \%)$, clinical improvement $(7.9 \%)$, and others $(18.0 \%)$ in the CT-P13 group. The incidence of adverse events of CT-P13, including infusion reaction $(n=10)$, mycobacterial infection $(n=2)$, and skin eruption $(n=1)$ was comparable to that of RINF.

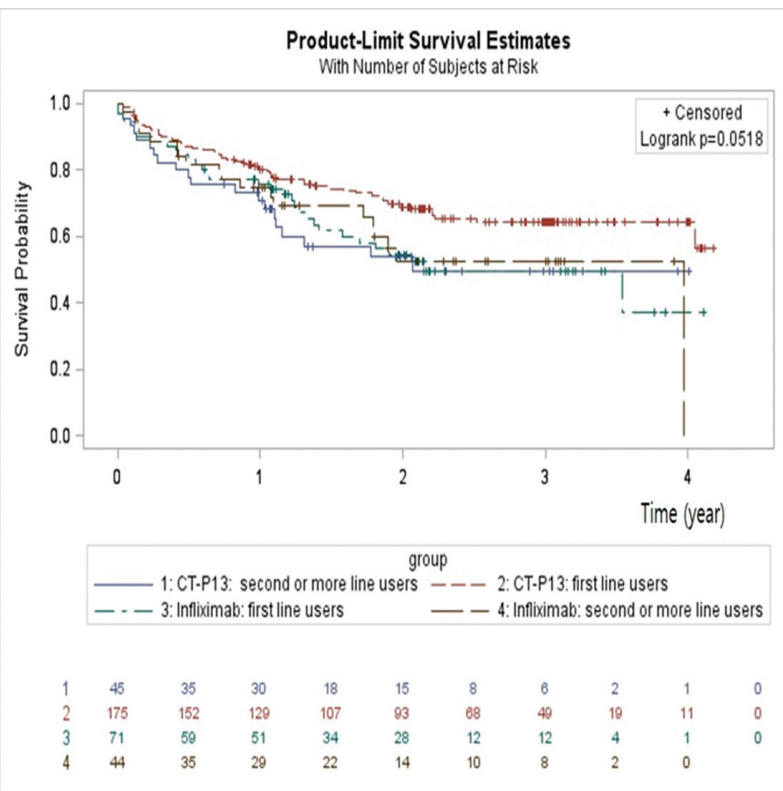

Conclusions: Our study demonstrates that the drug retention rate of CT-P13 especially in first-line users was relatively higher than that of RINF, [H1] and CT$\mathrm{P} 13$ showed a reasonable long-term safety profile in Korean AS patients.

Disclosure of Interest: None declared

DOI: 10.1136/annrheumdis-2018-eular.6182 